\title{
Effect of temperature and illumination on pyrite oxidation between pH 2 and 6
}

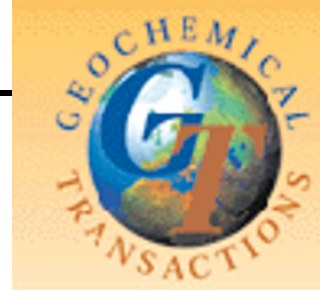

\author{
Martin Schoonen, ${ }^{a}$ Alicia Elsetinow, ${ }^{b}$ Michael Borda ${ }^{a}$ and Daniel Strongin ${ }^{b}$ \\ ${ }^{a}$ Department of Geosciences, SUNY-Stony Brook, Stony Brook NY 11794-2100, USA. \\ E-mail: mschoonen@notes.cc.sunysb.edu \\ ${ }^{b}$ Department of Chemistry, Temple University, Philadelphia PA 19122, USA
}

\section{Article}

\author{
Received 19th May 2000, Accepted 13th June 2000 \\ Published on the Web 4th July 2000
}

The effect of heat and illumination with visible light on the oxidation of pyrite with dissolved molecular oxygen in solutions between $\mathrm{pH} 2$ and 6 has been investigated using a combination of surface science experiments and batch oxidation experiments. The rate of the oxidation of pyrite is strongly dependent on temperature. It is, however, not possible to cast the temperature dependence in a simple Arrhenius equation because the magnitude of the activation energy depends on the progress variable chosen. Activation energies based on proton release rate, sulfate release rate, and total iron release rate vary by as much as $40 \mathrm{~kJ} \mathrm{~mol}^{-1}$, suggesting that the oxidation mechanism of the sulfur and iron component of pyrite are largely independent of each other. This difference in mechanism can also explain why the reaction rates on the basis of these three different progress variables do not show the same $\mathrm{pH}$ dependence. Exposed to visible light, the rate of pyrite oxidation is under most conditions accelerated by less than a factor of two. Some of this acceleration may be accounted for by a light-induced heating of the pyrite surface. Surface science experiments employing photoelectron spectroscopy show no evidence for significant changes in the chemical composition of the surface as a function of exposure to visible light. The batch sorption experiments show, however, that the reaction stoichiometry changes somewhat, which indicates that there might be a change in reaction mechanism as a result of exposure to visible light.

\section{Introduction}

Pyrite oxidation is an important process in the geochemical cycles of iron and sulfur. ${ }^{1,2}$ In aerobic near-surface aqueous environments, pyrite is thermodynamically unstable and oxidizes. In most aqueous environments, the oxidant for the reaction is either dissolved molecular oxygen [reaction (1)] or dissolved ferric iron [reaction (2)].

$$
\begin{gathered}
2 \mathrm{FeS}_{2}+7 \mathrm{O}_{2}+2 \mathrm{H}_{2} \mathrm{O} \rightarrow 2 \mathrm{Fe}^{2+}+4 \mathrm{SO}_{4}^{2-}+4 \mathrm{H}^{+} \\
\mathrm{FeS}_{2}+14 \mathrm{Fe}^{3+}+8 \mathrm{H}_{2} \mathrm{O} \rightarrow 15 \mathrm{Fe}^{2+}+2 \mathrm{SO}_{4}^{2-}+16 \mathrm{H}^{+} \\
2 \mathrm{Fe}^{2+}+1 / 2 \mathrm{O}_{2}+2 \mathrm{H}^{+} \rightarrow 2 \mathrm{Fe}^{3+}+\mathrm{H}_{2} \mathrm{O}
\end{gathered}
$$

The rate of the oxidation process in aqueous environments is under most conditions governed by the advection of molecular oxygen to the pyrite surface, regardless of whether the oxidant is $\mathrm{Fe}(\mathrm{III})$ or $\mathrm{O}_{2}$ itself. [Fe(III) may be the oxidant but its concentration in solution is controlled by the reaction between dissolved $\mathrm{Fe}(\mathrm{II})$ and $\mathrm{O}_{2},{ }^{3}$ reaction (3)]. Because abiotic pyrite oxidation in aqueous environments is a relatively slow process, there is the opportunity for microbes to catalyze the process. A number of field studies have documented the presence of various types of microbes that take advantage of the disequilibrium. ${ }^{4-9}$ In principle, microbes can promote the oxidation of pyrite via a direct enzymatic attack or through catalysis of a reaction step that does not involve the pyrite surface. While there is no consensus on this issue, a recent review of the literature on the subject by Nordstrom and Southam ${ }^{8}$ suggests that microbes promote the process indirectly by catalyzing the oxidation of $\mathrm{Fe}$ (II) to $\mathrm{Fe}$ (III) [reaction (3)]. The oxidation of $\mathrm{Fe}(\mathrm{II})$ can be catalyzed by planktonic as well as surface-bound microbes. ${ }^{5}$ Attached microbes induce changes in the chemical composition of the pyrite surface and induce the formation of etch pits, which increase the reactive surface area. ${ }^{5}$ Because the microbial catalysis of the process is thought to be largely due to the catalysis of reaction (3) and not through a direct enzymatic reaction, it is important to understand the abiotic oxidation process. As pyrite oxidation is the principal cause of the formation of acidic mine drainage (AMD), there has been an extensive effort to understand the mechanism of pyrite oxidation so that effective abatement strategies may be developed. Despite a very extensive effort involving experimental techniques ranging from various types of aqueous batch and flow-through experiments, ${ }^{10-17}$ to electrochemical studies, ${ }^{18-23}$ to spectroscopic studies, ${ }^{24-32}$ some key details of the reaction mechanism remain unclear.

In this study, the effect of photo activation with visible light and thermal activation (heat) on the abiotic process is evaluated through a combination of aqueous $\mathrm{pH}$-stat experiments and surface science experiments. It is of importance to evaluate the effect of light on pyrite oxidation because mine waste is often exposed to sunlight. As explained below in more detail, it is in principle possible that the mechanism of pyrite oxidation changes under the influence of visible light. The oxidation of pyrite is an exothermic process. If pyrite oxidation occurs in enclosed systems, such as underground mine galleries or in waste piles, the dissipation of the heat released by the oxidation process is often inefficient and, as a result, the temperature in the system rises. ${ }^{33,34}$ For example, temperatures in an abandoned mine gallery at Iron Mountain, Northern California, reach temperatures as high as $60{ }^{\circ} \mathrm{C} .{ }^{9}$ The temperature dependence of reaction (1) has been studied before, but values for the activation energy for this reaction range from 56 to $88 \mathrm{~kJ} \mathrm{~mol}^{-1}$. The results of this work show that the activation energy for pyrite oxidation varies with the $\mathrm{pH}$ and the choice of progress variable, which may explain the range in values reported earlier. 


\section{Background}

For the purpose of this study we briefly review two topics. These two topics are: (i) the physics and chemistry of the interaction of light with semiconductor particles, in particular pyrite and (ii) the choice of progress variable in experimental studies of pyrite oxidation.

\section{Interaction of light with pyrite}

Pyrite is a semiconductor with a sufficiently small band gap that it can be activated with visible light. ${ }^{23,35}$ There are several other literature sources that address in detail the interaction of light and solid-state matter ${ }^{36-38}$ as well as the general principles of photochemical reactions in particulate/water systems. ${ }^{38-43}$

A semiconductor is characterized by an electronic band structure in which there is a separation of up to $4 \mathrm{eV}$ between the top of the valence band and the bottom of the conduction band. If a semiconductor is irradiated with photons with an energy that exceeds the band gap energy, an electron from the valence band can be promoted to the conduction band, Fig. 1. The creation of a photoelectron in a semiconductor creates a vacancy in the valence band (hole). In essence, the creation of a photoelectron-hole pair renders a semiconductor into an activated state. Recombination of the photoelectron-hole pair with an associated release of heat is the most common process by which the activated state is dissipated. However, there is also the possibility that the photoelectron and hole react with sorbed electron acceptors and electron donors, respectively. Whether the activated state can be dissipated through a photochemical reaction, depends on the energy levels of the band edges and the frontier orbitals of the sorbed electron donor/acceptor. The transfer of the photoelectron to the lowest unoccupied molecular orbital (LUMO) of a sorbed electron acceptor is only possible if the energy levels of the LUMO and that of the bottom of the conduction band are close (Fig. 1). ${ }^{38}$ Similarly, the transfer of electrons from an absorbed electron donor to a hole requires that the energy level of the highest occupied molecular orbital of the donor is close to that of the top of the valence band (Fig. 1). Secondary effects such as the presence of impurities in the semiconductor, band bending, and surface charge induced by specific sorption will influence the energetics of the interaction between the photoelectron-hole pair and sorbed electron donors and acceptors. As a first approximation, it is useful to compare the energy levels of the band edges of the semiconductor to the standard redox potential of the aqueous electron donor/ acceptor. ${ }^{44}$ The energy position of band edges for about fifty semiconducting minerals have recently been calculated. ${ }^{44}$ Standard redox potentials for most aqueous redox species are readily available. ${ }^{45}$ It should be noted that even if the energetics of the band edges and frontier orbitals of the sorbate are favorable, symmetry mismatches can inhibit the reaction. In essence, the two electron-exchanging orbitals (one from the sorbate and one from the solid) must be able to overlap. A symmetry mismatch reduces the overlap and can inhibit an

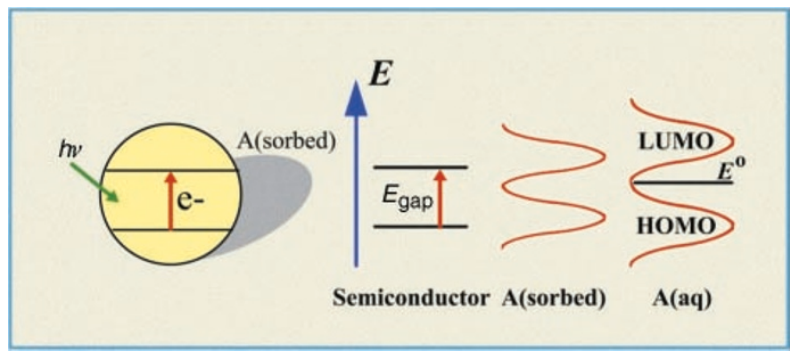

Fig. 1 Schematic representation of the relevant energy levels involved in the electron transfer between a semiconductor particle and an adsorbate (A). See text for details. energetically favorable reaction. While frontier orbital theory is readily applied to electron transfer reactions between molecules, ${ }^{46,47}$ it is more difficult to apply it to reactions involving solids because the symmetry of the orbitals (energy levels) of the solid involved in the electron exchange are often unknown. This uncertainty arises from the fact that surface sites and surface defect sites may have an orbital structure that differs from the bulk. ${ }^{43}$

The band structure and band gap energy for pyrite are both well known. Pyrite has a band gap of $0.95 \mathrm{eV},{ }^{35}$ which means that light with a wavelength shorter than $1309 \mathrm{~nm}$ can lead to excitation. ${ }^{42}$ The energy positions of the band edges have been experimentally determined in two studies and there are estimates on the basis of molecular orbital calculations. The results of these experimental and theoretical approaches are in poor agreement. ${ }^{44}$ It is important to eventually resolve the actual absolute position of the band edges because this determines which photochemical reactions can take place when pyrite is activated. Recent studies by Rosso and coworkers ${ }^{48,49}$ show that the HOMO and LUMO on a $\{100\}$ surface is a non-binding energy level dominated by contributions from the $\mathrm{Fe} 3 \mathrm{~d} \mathrm{t}_{2 \mathrm{~g}}$, with lesser contributions from $\mathrm{S} 3 \mathrm{p}$ and $\mathrm{Fe} 3 \mathrm{~d}_{z^{2}}$. The energy level is not filled, so it can both accept and donate electrons. Most importantly, the work by Rosso et $a_{l}{ }^{48,49}$ indicates that electron transfer reactions are most likely to proceed via $\mathrm{Fe}$ sites, rather than $\mathrm{S}$ sites.

Illumination of a semiconductor dispersed in an aqueous solution can cause decomposition of the solid. Most natural pyrites are n-type semiconductors. Illumination of an n-type semiconductor forces the hole $\left(\mathrm{h}^{+}\right)$to migrate to the interface. The hole can either react with an aqueous electron donor, including water, or it can be involved in an anodic dissolution reaction:

$$
\mathrm{FeS}_{2}+2 \mathrm{~h}^{+}=\mathrm{Fe}^{2+}+2 \mathrm{~S}(0)
$$

The reaction with water [reactions (5) and (6)] is expected to create reactive intermediates such as $\mathrm{OH}^{\bullet}$ and $\mathrm{H}_{2} \mathrm{O}_{2}$, which may in turn oxidize the surface.

$$
\begin{gathered}
\mathrm{h}^{+}+\mathrm{H}_{2} \mathrm{O}=\mathrm{H}^{+}+\mathrm{OH}^{-} \\
2 \mathrm{OH}^{\cdot}=\mathrm{H}_{2} \mathrm{O}_{2}
\end{gathered}
$$

Photoanodic dissolution or photocorrosion in general limits the usefulness of many semiconductors as photocatalysts. ${ }^{50}$ These same processes may very well also play a role in the stability of natural semiconductors in anaerobic aqueous systems. In aerobic waters, there will be a competition between photoanodic decomposition and oxidation via reactions (1) or (2). In the context of the present study it is important to point out that illumination may change the chemical composition of the surface via reaction (4) and that reactions (5) and (6) may be important in that they produce very reactive oxidants that can accelerate the oxidation process.

\section{Choice of reaction progress variable}

Earlier experimental work on the abiotic oxidation of pyrite has shown that the oxidation proceeds via a multi-step reaction sequence that is most likely initiated on iron surface sites. ${ }^{29,48,49}$ It is well known that oxygen and water must be present for pyrite oxidation to proceed. The oxygen is thought to oxidize a surface $\mathrm{Fe}(\mathrm{II})$ site into a $\mathrm{Fe}$ (III) site. Water is then disproportionated on these sites via a reaction equivalent to reaction (4), forming a hydroxy radical and/or hydrogen peroxide. These species can then attack the disulfide group. The disulfide group is probably stepwise oxidized to a thiosulfate-like surface complex, which disproportionates to elemental sulfur and sulfate, with sulfate leaving the surface. The notion of progressive oxidation of the disulfide group is supported by 
modern surface science studies. ${ }^{29}$ XPS studies report sulfur with oxidation states that match those of thiosulfate and sulfate, while with in situ Raman spectroscopy the presence of elemental sulfur has been established. XPS studies require that the samples are studied under a vacuum of about $10^{-10}$ Torr $(1$ Torr $\approx 133.322 \mathrm{~Pa}$ ), which may lead to a preferential loss of elemental sulfur and bias the observations somewhat. Because sulfate is the dominant sulfoxyanion found in aqueous studies the build up of elemental sulfur and sulfoxyanions with sub-vI oxidation state suggest that these surface-bound products are relatively stable intermediates in a sequence of reactions leading to aqueous sulfate. The fate of iron depends strongly on the $\mathrm{pH}$ of the solution. In solutions with a $\mathrm{pH}$ below about 3 , the iron is released to solution; while at higher $\mathrm{pH}$, the surface becomes decorated with $\mathrm{Fe}$ (III)-oxide patches as the reaction proceeds. ${ }^{51}$ These oxide patches are thought to facilitate the transfer of electrons between dissolved molecular oxygen and the underlying pristine pyrite surface. ${ }^{13,51}$ Hence, it may be expected that above $\mathrm{pH} 3$ the rate of the oxidation process increases.

One particularly nettlesome problem is the choice of progress variable(s). There are several possible variables that can be used to quantify the progress of the reaction. One approach is to measure the loss of pyrite after exposure to an oxidizing solution for a known period of time. ${ }^{15,52,53}$ This works well if the extent of the reaction is at least a few percent and care must be taken to remove any secondary products. A drawback is that with this method only one data point can be collected per experiment. In most studies, rate data have been obtained during an experiment by periodically determining either sulfate (or total sulfoxyanions) or total iron released to solution. Total iron is a poor progress variable in solutions with a $\mathrm{pH}$ above 4 because ferric iron is relatively insoluble in near neutral to alkaline solutions. Sulfate is perhaps a better choice, but the amount of sulfate released may not always directly reflect the rate of pyrite oxidation. For example, if pyrite is oxidized and most of the disulfide is converted to surface-bound elemental sulfur rather than sulfate then the rate of reaction may be underestimated. Furthermore, the use of sulfate is complicated in studies where the initial rate method is employed. In earlier work, our group has shown that sulfur-deficient defects initiate the oxidation process on pristine pyrite surfaces. ${ }^{29,32}$ These sulfur-deficient defect sites disproportionate water and lead to the formation of sulfate on the surface, which is easily transferred to the solution. Hence, even in the absence of an aqueous oxidant, such as $\mathrm{O}_{2}$ or $\mathrm{Fe}^{3+}$, a pristine pyrite surface will generate some sulfate in solution upon contact with water. This explains the fact that in many aqueous studies there is an immediate release of sulfate into solution as particles are suspended in water. This initial sulfate release makes it more difficult to extract meaningful rate data using the initial rate method.

A third possible reaction progress variable is the $\mathrm{O}_{2}$ consumption rate, $R_{\mathrm{O}_{2}}$. Pyrite oxidation consumes molecular oxygen and, therefore, $R_{\mathrm{O}_{2}}$ can be used as a progress variable. Dissolved molecular oxygen can be measured in situ using a polarographic $\mathrm{O}_{2}$ probe. Kamei and Ohmoto ${ }^{54}$ used $R_{\mathrm{O}_{2}}$ in a recent study to evaluate the oxidation rate of pyrite in solutions with $\mathrm{pH}$ values between $\mathrm{pH} 5$ and 6.4. A drawback of this method is that the dynamic range is limited and that most $\mathrm{O}_{2}$ probes can not be used above about $40^{\circ} \mathrm{C}$.

A fourth possible reaction progress variable that can be used in solutions with $\mathrm{pH}$ values above 2.5 is the rate of acid production. In a pH-stat experiment it is straightforward to derive the acid production rate, $R_{\mathrm{H}}$. However, to extract a pyrite oxidation rate from $R_{\mathrm{H}}$ the stoichiometry of the reaction must be known. This can be seen from reactions (1)-(3). Without measuring either the rate of $\mathrm{Fe}$ or $\mathrm{SO}_{4}{ }^{2-}$ production $\left(R_{\mathrm{Fe}}, R_{\mathrm{SO}_{4}}\right)$ in concert with $R_{\mathrm{H}}$ it is impossible to determine how $R_{\mathrm{H}}$ relates to the rate of pyrite oxidation. If reaction (1) is the dominant reaction, then one expects that $R_{\mathrm{SO}_{4}}: R_{\mathrm{Fe}}: R_{\mathrm{H}}=$ $1: 0.5: 1$. On the other hand, if reactions (1) and (3) are combined, then the expected ratio changes to $1: 0.5: 0.5$. Because iron can only be used as a progress variable below $\mathrm{pH} 3$, it is convenient to only consider the ratio $R_{\mathrm{H}} / R_{\mathrm{SO}_{4}}$ Hence, in acid solutions, the ratio $R_{\mathrm{H}} / R_{\mathrm{SO}_{4}}$ is expected to have a value between 0.5 and 1 . In near neutral solutions to alkaline solutions the ratio is expected to attain a value of 2, as reaction (7) is expected to dominate the stoichiometry of the oxidation process.

$$
2 \mathrm{FeS}_{2}+7.5 \mathrm{O}_{2}+7 \mathrm{H}_{2} \mathrm{O} \rightarrow 2 \mathrm{Fe}(\mathrm{OH})_{3}(\mathrm{~s})+4 \mathrm{SO}_{4}^{2-}+8 \mathrm{H}^{+}
$$

Hence, by determining $R_{\mathrm{H}}$ as well as $R_{\mathrm{SO}_{4}}$ it is possible to constrain the stoichiometry of the overall reaction. Also, any deviation from the expected $R_{\mathrm{SO}_{4}} / R_{\mathrm{H}}$ may yield some insight into the reaction stoichiometry.

With up to four progress variables that may be used to quantify the pyrite oxidation rate, the activation energy for the process may be determined on the basis of as many as four different progress variables. The activation energies reported in earlier work have mostly been based on rates using either sulfate or iron release, but never both. In the study by Kamei and Ohmoto, ${ }^{54}$ activation energies for the process were calculated on the basis of $R_{\mathrm{O}_{2}}$. The reported activation energies range from about 50 to 88 . In this study, activation energies have been derived on the basis of $R_{\mathrm{H}}, R_{\mathrm{SO}_{4}}$, as well as $R_{\mathrm{Fe}}$, if possible.

\section{Experimental methods}

In this study a combination of aqueous $\mathrm{pH}$-stat experiments as well as surface science experiments using ultra high-vacuum (UHV) techniques were conducted. The methods for each of these two types of experiments are briefly described below.

\section{Surface science experiments}

Electron spectroscopic data presented in this study were obtained in a stainless steel UHV chamber, with a working base pressure of $1 \times 10^{-9}$ Torr, combined with a high pressure reaction cell. Details of this chamber can be found in a prior publication. ${ }^{30}$ The reaction cell allows samples to be transferred from vacuum to atmospheric pressure without exposure to the ambient laboratory environment.

Naturally grown $\{100\}$ Pyrite used in UHV experiments was acquired from Logrono, Spain and cut to produce a $1 \mathrm{~cm}^{2} \times$ $2 \mathrm{~mm}\{100\}$ growth surface. Through a combination of ion bombardment and acid rinsing in $0.5 \mathrm{M} \mathrm{HCl}$, an atomically clean and relatively well ordered surface was obtained. Specifics concerning the structure of this surface have been published previously. ${ }^{32}$

$\{100\}$ Pyrite was exposed to ultra-violet light in the highpressure reaction cell through a quartz window. The light source was a xenon-mercury lamp mounted in an Oriel model C-60-50 housing, powered by a Schoeffel LPS 255 lamp power supply in sequence with a Schoeffel model 359 arc lamp igniter. Infrared light was filtered from the source by using a $20 \mathrm{~cm}$ long quartz water filter. Exposure to light was carried out for $5 \mathrm{~h}$ in a 1 bar dry nitrogen background.

X-ray photoelectron spectroscopy (XPS) was carried out by using $\mathrm{Mg} \mathrm{K} \alpha(1253.6 \mathrm{eV})$ unmonochromatized radiation in combination with a double-pass cylindrical mirror analyzer (CMA). The pass energy of the electrons that were analyzed was $25 \mathrm{eV}$.

\section{Aqueous pH-stat experiments}

Oxidation experiments on slurries of crushed pyrite (Huanzala, Peru) were conducted in a $1 \mathrm{~L}$, glass, air-tight, magneticallystirred vessel equipped with a water jacket (Ace Glass $\mathrm{II}$ ) (see 
Fig. 2). The vessel was mounted on an optical bench at $45 \mathrm{~cm}$ from a $1000 \mathrm{~W}$ xenon lamp. The xenon lamp (Hanovia $(\mathrm{IM}-\mathrm{C} 50$ ) is mounted in a Schoeffel $\mathrm{IIM}$ C-60 lamp housing and connected to a power supply (Schoeffel $\mathrm{im}$ LP255). The luminosity of the lamp was regulated by the current delivered to the lamp by the power supply. The light generated by the xenon lamp was passed through three $2.5 \mathrm{~cm}$ quartz water filters as well as the water jacket of the vessel to remove the IR radiation and effectively cool the light beam. The photochemistry experiments were conducted at a light intensity of 0.0289 einstein $\mathrm{L}^{-}$ ${ }^{1} \mathrm{~h}^{-1}$ (mol photons $\mathrm{L}^{-1} \mathrm{~h}^{-1}$ ), which is equivalent to ten-fold (0.002 einstein $\mathrm{L}^{-1} \mathrm{~h}^{-1}$ ) times greater than the intensity of sunlight. The light intensity as a function of current was measured in a set of actinometry experiments using the Fe(III)oxalate actinometer. ${ }^{55}$ Water from a constant-temperature water bath equipped with a thermostat-controlled cooling unit (Neslab(iM) IBC-4) as well as a thermostat-controlled (Brinkmann (iim) heater was pumped through the water jacket of the glass vessel. The temperature in the vessel was measured using a K-type thermocouple inserted through one of four ports in the lid of the vessel. The $\mathrm{pH}$ in the slurry was kept constant using a Titroline Alpha $(\mathrm{II}) \mathrm{pH}$-Stat equipped with a double junction, gel-filled $\mathrm{pH}$ electrode (Fisher(II)) and a Pt temperature probe. The temperature probe was immersed in the water bath and controls the automatic temperature corrections made on the $\mathrm{pH}$ measurement in the $\mathrm{pH}$ stat. Standard $\mathrm{pH}$-buffer solutions were used to calibrate the $\mathrm{pH}$ electrode at the start of the experiment and assess the drift in the $\mathrm{pH}$ electrode at the conclusion of the experiment. In experiments that ran for more than two days, the $\mathrm{pH}$-stat control was temporarily suspended to recalibrate the $\mathrm{pH}$ electrode. Typically, the $\mathrm{pH}$ drift was less than $0.05 \mathrm{pH}$ units over a $24 \mathrm{~h}$ period. Standardized $0.01 \mathrm{M}$ $\mathrm{NaOH}$ solutions (Chemlab $(\mathrm{II})$ ) were automatically titrated into the vessel to maintain the $\mathrm{pH}$ at the desired value. The $\mathrm{pH}$-stat unit records the amount of base added as a function of time so a rate of acid production in the vessel can be obtained.

At the start of each experiment the vessel was charged with $750 \mathrm{~mL}$ of deionized water. For about $1 \mathrm{~h}$ the water was purged with $\mathrm{N}_{2}$ gas. The $\mathrm{N}_{2}$ gas was passed through a catalytic oxygen trap (Alltech $\mathbb{I}$ ) and bubbled through a concentrated alkaline sulfite solution, a concentrated $\mathrm{KOH}$ solution and deionized water to remove any residual oxygen and carbon dioxide. Earlier work has shown that this is an effective method to remove dissolved molecular oxygen. ${ }^{56}$ In one experiment, we determine the change in dissolved molecular oxygen using an Orion (IM) DO meter and found that within about 30 min the $\mathrm{O}_{2}$ level drops below the detection limit of the meter $\left(0.01 \mathrm{mg} \mathrm{L}^{-1}\right)$. Subsequently, $3 \mathrm{~g}$ of acid-washed pyrite is added to the vessel while the vessel is kept under a $\mathrm{N}_{2}$ atmosphere. Once the pyrite is dispersed, the $\mathrm{pH}$ control is initiated and the vessel wrapped in Al-foil. To hydrate and equilibrate the pyrite surface, the slurry is kept under a $\mathrm{N}_{2}$ atmosphere for at least $12 \mathrm{~h}$. In this equilibration period the $\mathrm{pH}$ tends to drift up for a few hours before it stabilizes, so we used a standardized acid solution $(0.02 \mathrm{M} \mathrm{HCl})$ to maintain the $\mathrm{pH}$ constant. (During this initial equilibration period, the surface is likely to undergo hydration reactions, partial dissolution, and iron monosulfide defects at the surface may react. Similar increases in $\mathrm{pH}$ at the start of a batch oxidation experiment have been reported by Kamei and Ohmoto $^{54}$.) After the equilibration period, the titrant is changed to standardized base and the gas stream switched to pure oxygen scrubbed for $\mathrm{CO}_{2}$ by passing it through a $\mathrm{KOH}$ solution. At preset time intervals ( 2 to 10 min depending on the rate of reaction) the cumulative amount of base added is recorded and periodically $5 \mathrm{~mL}$ aliquots were withdrawn through a sample port fitted with a filter. The samples were analyzed for sulfate using an automated ion chromatograph (Dionex $\mathrm{IM})$ DX 500) equipped with a AS4A-SC column. Initially, we also analyzed the samples for thiosulfate but we rarely found any appreciable amount of thiosulfate and in later experiments we limited the analyses to sulfate only. In experiments below $\mathrm{pH} 4$, total iron was determined in the samples using Hach $(\mathrm{II})$ Ferrozine method $\left(\mathrm{Hach}_{\mathbb{I} \mathrm{II}}\right)$ method 8147). To evaluate the effect of light on the reaction rate, the oxidation rate in the dark was measured first, then the foil was taken off the vessel and the lamp ignited. After the rate was determined in the dark and light, the temperature was increased and the sequence of dark-light measurements was repeated. Hence, a single slurry was equilibrated at a pH between 2 and 6 and then measurements were conducted under a number of illumination and temperature conditions. In several experiments, we measured the oxidation rate on the same slurry at the same conditions several days apart and found that there was a good agreement. We attribute this to the fact that in those experiments the reaction progress was never more than a fraction of $1 \%$. Hence, the reaction rate in those experiments was not limited by the availability of pyrite as the reaction proceeds, although the reactivity of the surface may somewhat change. In two experiments at $\mathrm{pH} 3$ (P21 and P22), the reaction progress approached $25 \%$ as defined by the amount of sulfate released. In those two experiments we noted that the rate of reaction decreased significantly toward the end of the experiment. Because the reactions progressed well beyond $1 \%$, we determined the rate of oxidation as a function of temperature in the dark in experiment P21 and repeated the experiment under illumination in experiment P22. P21 and P22 were conducted with the same batch of starting material.

A set of control experiments was conducted to evaluate how illumination affected the temperature of the pyrite slurry. As noted above, illumination of a semiconductor may raise the temperature of the particle as the excited state resulting from the capture of a photon is dissipated through recombination of the photoelecton-hole pair. In the control experiments, the temperature of a homogeneous solution, two different pyrite slurries, and a ZnS slurry were measured as the $1000 \mathrm{~W}$ lamp was turned on and off. The experiments were conducted under the exact same conditions as in the oxidation experiments, except that these control experiments were conducted under nitrogen. The temperature was measured using a K-type thermocouple immersed in the solution/slurry.

The surface area of the starting material was measured and for several experiments a surface area measurement was also conducted on the reacted material. All measurements were conducted with mutli-point $\mathrm{Kr}$ BET on a Quantachrome instrument $\mathrm{IM}$. However, there is considerable uncertainty in the accuracy of these data. A reagent grade calcite powder submitted to two independent laboratories using the same method and model instrument gave Kr-BET surface area values that were off by a factor of 3 . In this study, we used a total of four different batches of starting material. Although all batches of starting material were prepared by the same method, some difference in specific surface area is to be expected. Given the uncertainty in the accuracy of the BET measurements, comparisons between experiments conducted with different starting materials and, therefore, different $\mathrm{pH}$ conditions may not be relevant. Because reaction rates were determined as a function of $T$ and illumination on a single slurry for a given $\mathrm{pH}$, it is relevant to evaluate changes in the reaction rate as function of $T$ and illumination.

\section{Results}

In this section the results of the surface science experiments and $\mathrm{pH}$ stat experiments are presented separately.

\section{Surface science experiments}

Experiments were performed to investigate whether the structure of pyrite was altered during the illumination experiments. These experiments were performed by illuminat- 


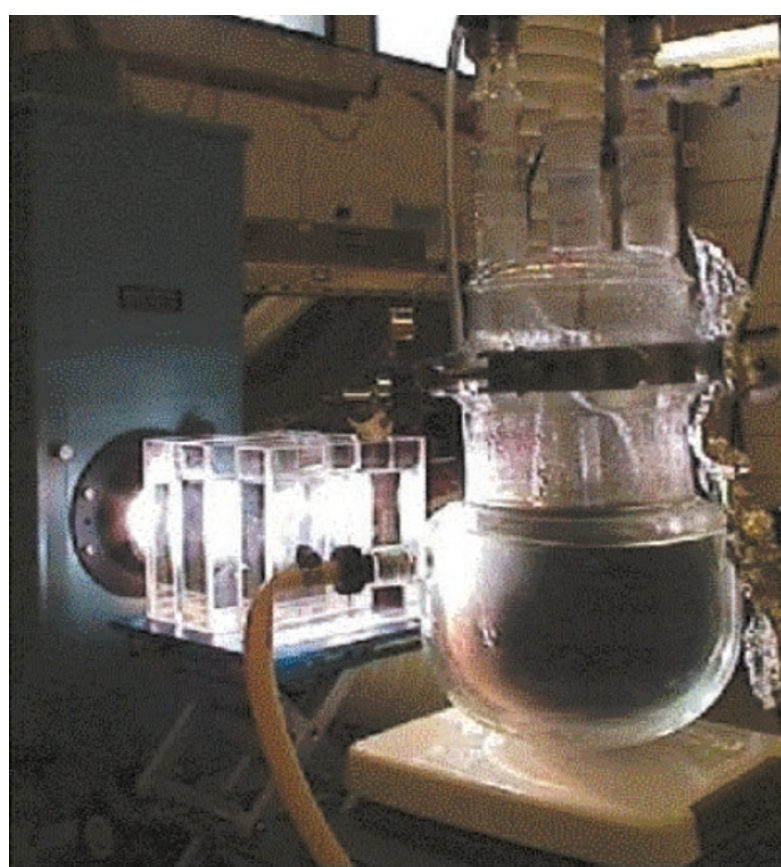

Fig. 2 Reaction vessel on optical bench used in this study.

ing pyrite in an inert atmosphere of dry nitrogen (see Experimental section). Fig. 3 exhibits $\mathrm{S} 2 \mathrm{p}$ and $\mathrm{Fe} 2 \mathrm{p}_{3 / 2}$ data for $\{100\}$ pyrite before and after exposure to ultra-violet light. Consistent with prior XPS research of pyrite, the $\mathrm{S} 2 \mathrm{p}$ region was fitted with at least two features at 162.4 and $161.5 \mathrm{eV}$, associated with sulfur in the disulfide group and in a monosulfide impurity, respectively. ${ }^{24,29}$ Illumination of this surface for $5 \mathrm{~h}$ with the Xe lamp led to no significant changes in

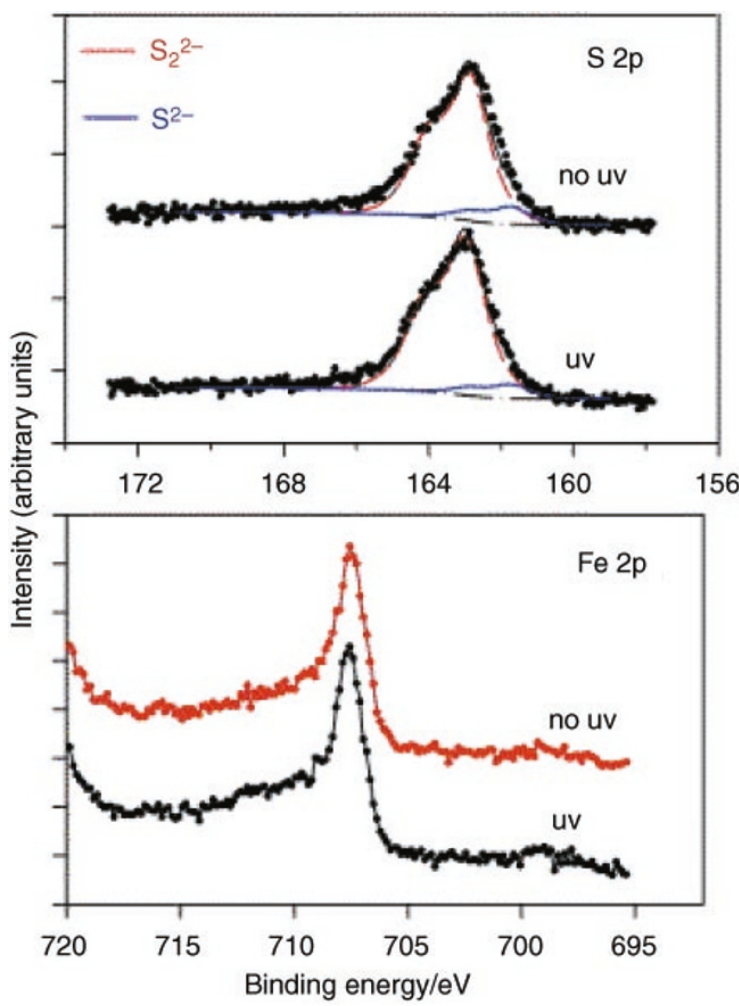

Fig. 3 Top panel: S $2 \mathrm{p}$ data for $\{100\}$ pyrite, with and without uv illumination. A S $2 p_{3 / 2}-2 p_{1 / 2}$ splitting of $1.18 \mathrm{eV}$ and $2: 1$ relative peak area, along with a full width half maximum of $1.3 \mathrm{eV}$ for each $\mathrm{S} 2 \mathrm{p}$ feature has been used to fit the data. Bottom panel: Fe $2 \mathrm{p}_{3 / 2}$ data for $\{100\}$ pyrite with and without UV illumination. Both the $\mathrm{S} 2 \mathrm{p}$ and $\mathrm{Fe}$ $2 p_{3 / 2}$ data suggest that UV illumination does not lead to significant changes in the pyrite structure under our experimental conditions. the pyrite surface. Specifically, the disulfide and monosulfide contributions to the $S 2 p$ region were largely unchanged with respect to relative intensity and binding energy position. Furthermore, complimentary $\mathrm{Fe} 2 \mathrm{p}_{3 / 2}$ data also show that, within the resolution of the XPS experiment, illumination of the pyrite surface did not lead to any experimentally observable changes in the structure. It is pointed out however that, due to the relatively large sampling depth of XPS, small changes in the surface structure (due to the UV photons) would be difficult to discern from such an experiment. More detailed and surface sensitive photoelectron spectroscopy using synchrotron radiation would better address any possible UV-induced damage. These data do, however, suggest that the light does not macroscopically alter the pyrite $\{100\}$ structure and probably does not change the structure of the pyrite particles used in the aqueous studies. Rosso and co-workers ${ }^{49}$ have shown recently that the exposure of pyrite to $\mathrm{He} \mathrm{I}(21.2 \mathrm{eV})$ radiation in ultraviolet photoelectron spectroscopy (UPS) experiments altered the structure of a pyrite $\{100\}$ surface. We suspect that in this prior work the secondary electrons generated during the UPS experiment may have been a contributing factor in changing the pyrite structure. It cannot be ruled out, however, that changes in the pyrite structure due to illumination may simply be more observable in the UPS experiment, which directly probes the valence structure of the surface, with an expected greater surface sensitivity than the XPS experiment.

\section{Illumination control experiments}

While the results of the UHV experiments indicate that the surface of the pyrite does not change significantly, illumination may increase the temperature of the surface. In experiments designed to determine the activation energy of the reaction, it is important to be able to separate thermal effects from photochemical effects. The control experiments in which the temperature of a homogeneous solution, two pyrite slurries, and a zinc sulfide slurry were determined as a function of illumination, are shown in Fig. 4. Upon exposure to visible light, the temperature in the pyrite slurry increased by about $1.5^{\circ} \mathrm{C}$ within a few minutes, $1.0^{\circ} \mathrm{C}$ higher than the temperature increase seen in the homogeneous solution or the $\mathrm{ZnS}$ solution. The $\mathrm{ZnS}$ solution is expected to have little interaction with visible light because of its large band gap $(4 \mathrm{eV})$.

\section{pH-stat experiments}

The objectives of this study were to determine the effect of illumination and heat on the rate of pyrite oxidation. In each batch oxidation experiment, two and sometimes three progress variables were monitored in order to quantify the rate of pyrite

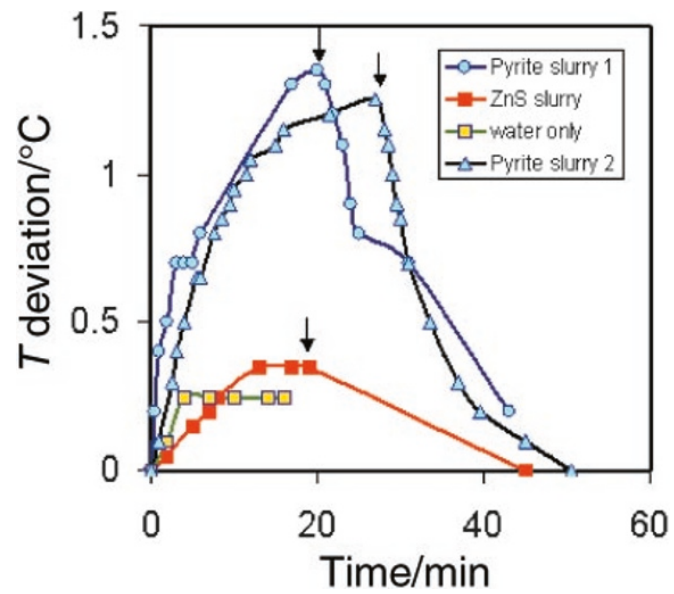

Fig. 4 Effect of illumination on temperature of metal sulfide slurries Arrows indicate points in time when the Xe lamp was turned off. See text for details. 
oxidation. The results for an experiment at $\mathrm{pH} 3$, the only $\mathrm{pH}$ condition that permits the monitoring of all three variables, are presented in Fig. 5. In this particular experiment, the temperature was raised from 23 to $46^{\circ} \mathrm{C}$ in four steps, while the slurry was kept in the dark. At each of these steps the three progress variables $\left[\mathrm{Fe}_{\mathrm{tot}}, \mathrm{SO}_{4}{ }^{2-}\right.$ and $\mathrm{H}^{+}$(measured as $\mathrm{NaOH}$ uptake)] were determined. Of these three variables, the proton release rate is best constrained because it is recorded every 2 to $4 \mathrm{~min}$. However, at the beginning of the experiment there is no detectable net proton release. Furthermore, when the temperature is raised, the net proton release tends to approach zero for several hours. An initial induction period in net proton release, as seen in Fig. 5, has been observed in several experiments, but not in all (see, e.g., Fig. 6). After the initial induction period passes, the proton release rate is essentially constant. The results are summarized in Table 1. This table is also available online (http://sbmp97.ess.sunysb.edu/archive. htm).

The absolute pyrite oxidation rates determined in this study are in reasonable agreement with earlier work. Most experimental work on pyrite oxidation has been conducted in acid conditions, in the dark, and near room temperature. On the basis of experiments conducted under those conditions we obtain the following rate data expressed in $\mathrm{mol} \mathrm{m}^{-2} \mathrm{~s}^{-1}: 10^{-8.66}$ based on $R_{\mathrm{SO}_{4}}, 10^{-8.77}$ on the basis of $R_{\mathrm{Fe}}$, and $10^{-8.75}$ on the basis of $R_{\mathrm{H}}$. A compilation of pyrite oxidation by dissolved molecular oxygen gives a range of $10^{-9.52}$ to $10^{-8.52}$.

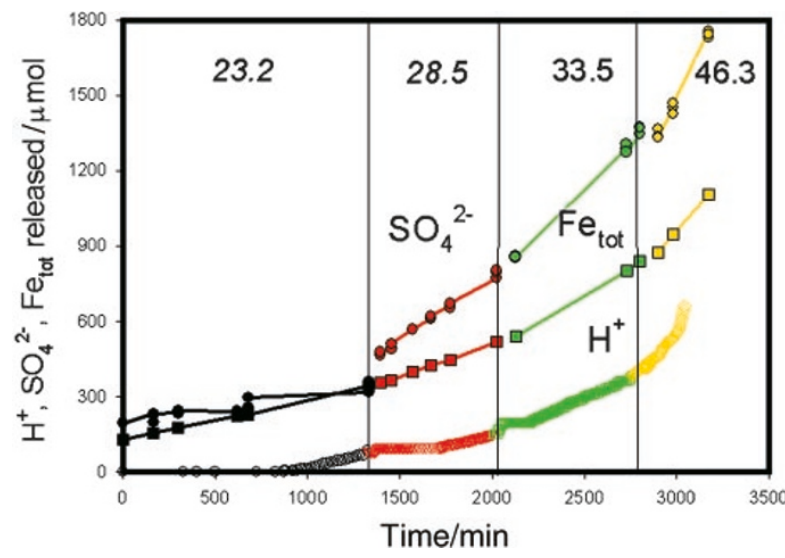

Fig. 5 Pyrite oxidation experiment at $\mathrm{pH}_{3}$ in the dark (P21). Temperature of slurry was increased stepwise. All three progress variables measured in this experiment are shown: $\mathrm{H}^{+}$(top), $\mathrm{Fe}_{\text {tot }}$ (middle), $\mathrm{SO}_{4}{ }^{2-}$ (bottom). All three variables are in units of micromol released to solution.

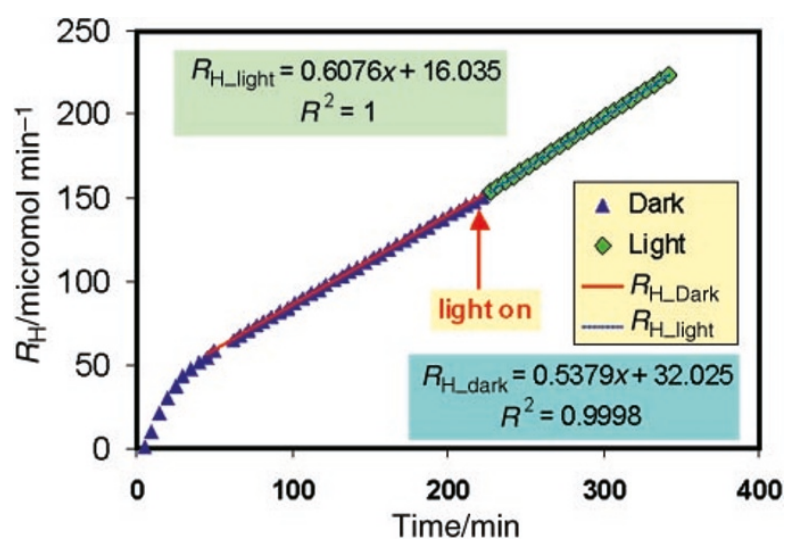

Fig. 6 Example of an experiment in which the oxidation rate of pyrite is first determined in the dark and then under illumination. Note how the release rate of protons is constant after an intial period of rapid proton release. Experiment P12, pH 5.
Table 1 Summary of oxidation rates. All rates in $\mu \mathrm{mol} \mathrm{m}{ }^{-2}$ min

\begin{tabular}{|c|c|c|c|c|c|c|}
\hline $\mathrm{pH}$ & $T /^{\circ} \mathrm{C}$ & Dark/light & $R_{\mathrm{H}}$ & $R_{\mathrm{SO}_{4}}$ & $R_{\mathrm{Fe}}$ & Experiment \\
\hline 2.3 & 19.8 & Dark & $\mathrm{nd}^{a}$ & 0.175 & $\mathrm{nd}^{a}$ & P20 \\
\hline 2.3 & 26.4 & Dark & $\mathrm{nd}^{a}$ & 0.879 & 0.159 & $\mathrm{P} 20$ \\
\hline 2.3 & 35.3 & Dark & $\mathrm{nd}^{a}$ & 0.317 & 0.215 & $\mathrm{P} 20$ \\
\hline 2.3 & 41.3 & Dark & $\mathrm{nd}^{a}$ & 0.661 & 0.345 & P20 \\
\hline 2.3 & 42.6 & Light & $\mathrm{nd}^{a}$ & 0.190 & 0.157 & $\mathrm{P} 20$ \\
\hline 3 & 25 & Dark & 0.017 & 0.049 & 0.033 & P11 \\
\hline 3 & 26 & Light & 0.088 & 0.072 & 0.035 & P11 \\
\hline 3 & 23.2 & Dark & 0.122 & 0.075 & 0.116 & P21 \\
\hline 3 & 28.5 & Dark & 0.129 & 0.359 & 0.185 & $\mathrm{P} 21$ \\
\hline 3 & 33.5 & Dark & 0.237 & 0.528 & 0.313 & $\mathrm{P} 21$ \\
\hline 3 & 46.3 & Dark & 0.545 & 1.069 & 0.611 & $\mathrm{P} 21$ \\
\hline 3 & 22.8 & Light & $\mathrm{nd}^{a}$ & 0.311 & 0.205 & $\mathrm{P} 22$ \\
\hline 3 & 30.7 & Light & 0.155 & 0.463 & 0.337 & $\mathrm{P} 22$ \\
\hline 3 & 36.5 & Light & 0.366 & 0.890 & 0.577 & $\mathrm{P} 22$ \\
\hline 3 & 43.7 & Light & 0.617 & 1.682 & 0.886 & P22 \\
\hline 4 & 26.5 & Dark & 0.090 & 0.087 & $\mathrm{nd}^{a}$ & P13 \\
\hline 4 & 33.9 & Dark & 0.294 & 0.233 & $\mathrm{nd}^{a}$ & $\mathrm{P} 13$ \\
\hline 4 & 39 & Dark & 0.527 & 0.334 & $\mathrm{nd}^{a}$ & P13 \\
\hline 4 & 43.5 & Dark & 0.765 & 0.393 & $\mathrm{nd}^{a}$ & P13 \\
\hline 4 & 26.5 & Light & 0.110 & 0.165 & $\mathrm{nd}^{a}$ & P13 \\
\hline 4 & 29.5 & Light & 0.250 & 0.144 & $\mathrm{nd}^{a}$ & P13 \\
\hline 4 & 34 & Light & 0.361 & 0.175 & $\mathrm{nd}^{a}$ & P13 \\
\hline 4 & 42.2 & Light & 1.420 & 0.670 & $\mathrm{nd}^{a}$ & P13 \\
\hline 5 & 20 & Dark & 0.113 & $\mathrm{nd}^{a}$ & $\mathrm{nd}^{a}$ & $\mathrm{P} 12$ \\
\hline 5 & 30 & Dark & 0.198 & $\mathrm{nd}^{a}$ & $\mathrm{nd}^{a}$ & $\mathrm{P} 12$ \\
\hline 5 & 40.5 & Dark & 0.860 & $\mathrm{nd}^{a}$ & $\mathrm{nd}^{a}$ & P12 \\
\hline 5 & 21 & Light & 0.176 & $\mathrm{nd}^{a}$ & $\mathrm{nd}^{a}$ & $\mathrm{P} 12$ \\
\hline 5 & 32.5 & Light & 0.604 & $\mathrm{nd}^{a}$ & $\mathrm{nd}^{a}$ & $\mathrm{P} 12$ \\
\hline 5 & 41 & Light & 1.261 & $\mathrm{nd}^{a}$ & $\mathrm{nd}^{a}$ & P12 \\
\hline 5 & 26.5 & Dark & 0.730 & 0.879 & $\mathrm{nd}^{a}$ & $\mathrm{P} 23$ \\
\hline 5 & 36.5 & Dark & 2.224 & 1.599 & $\mathrm{nd}^{a}$ & P23 \\
\hline 5 & 47.2 & Dark & 3.916 & 2.141 & $\mathrm{nd}^{a}$ & $\mathrm{P} 23$ \\
\hline 5 & 27.1 & Light & 0.940 & 0.615 & $\mathrm{nd}^{a}$ & P23 \\
\hline 5 & 35.7 & Light & 1.639 & 2.239 & $\mathrm{nd}^{a}$ & $\mathrm{P} 23$ \\
\hline 5 & 44 & Light & 2.671 & 4.164 & $\mathrm{nd}^{a}$ & $\mathrm{P} 23$ \\
\hline 6 & 24.6 & Dark & 0.330 & 0.172 & $\mathrm{nd}^{a}$ & P18 \\
\hline 6 & 29.1 & Dark & 0.534 & 0.334 & $\mathrm{nd}^{a}$ & P18 \\
\hline 6 & 34.65 & Dark & 0.856 & 0.315 & $\mathrm{nd}^{a}$ & P18 \\
\hline 6 & 24.5 & Light & 0.345 & 0.272 & $\mathrm{nd}^{a}$ & P18 \\
\hline 6 & 31.15 & Light & 0.545 & 0.226 & $\mathrm{nd}^{a}$ & P18 \\
\hline 6 & 36.4 & Light & 0.816 & 0.347 & $\mathrm{nd}^{a}$ & P18 \\
\hline
\end{tabular}

Illumination of the pyrite slurries increases in most experiments the oxidation rate (e.g., P12 Fig. 6). This is further illustrated in Fig. 7, where $R_{\mathrm{H}}, R_{\mathrm{SO}_{4}}$, and $R_{\mathrm{Fe}}$ for dark and light conditions determined at approximately the same temperature on the same slurry are compared. There is potentially some bias in the data. Rate measurements under light are measured after the measurements in the dark. If the extent of a reaction is well above $1 \%$, then the available reactive surface area is expected to have decreased between the measurements in the dark and light. For example, the oxidation rates under illumination for

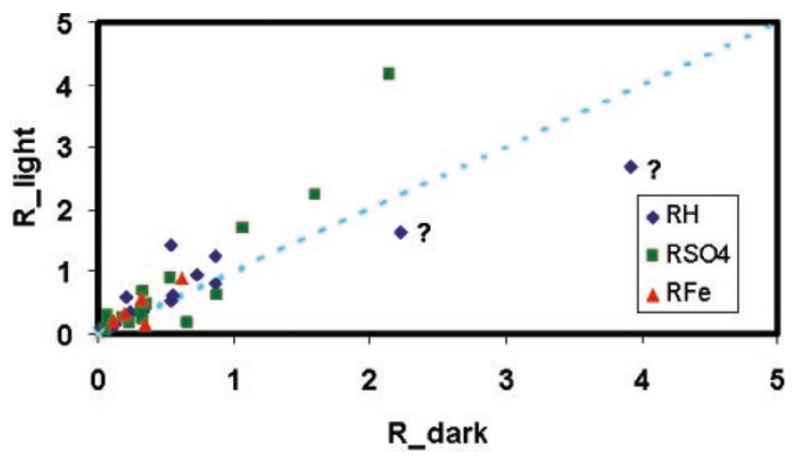

Fig. 7 Comparison of pyrite oxidation rates determined in the dark and under illumination with visible light. The oxidation rate measured in the light for the two data points labelled with question marks may be affected by a decrease in reactive surface area, see text. 

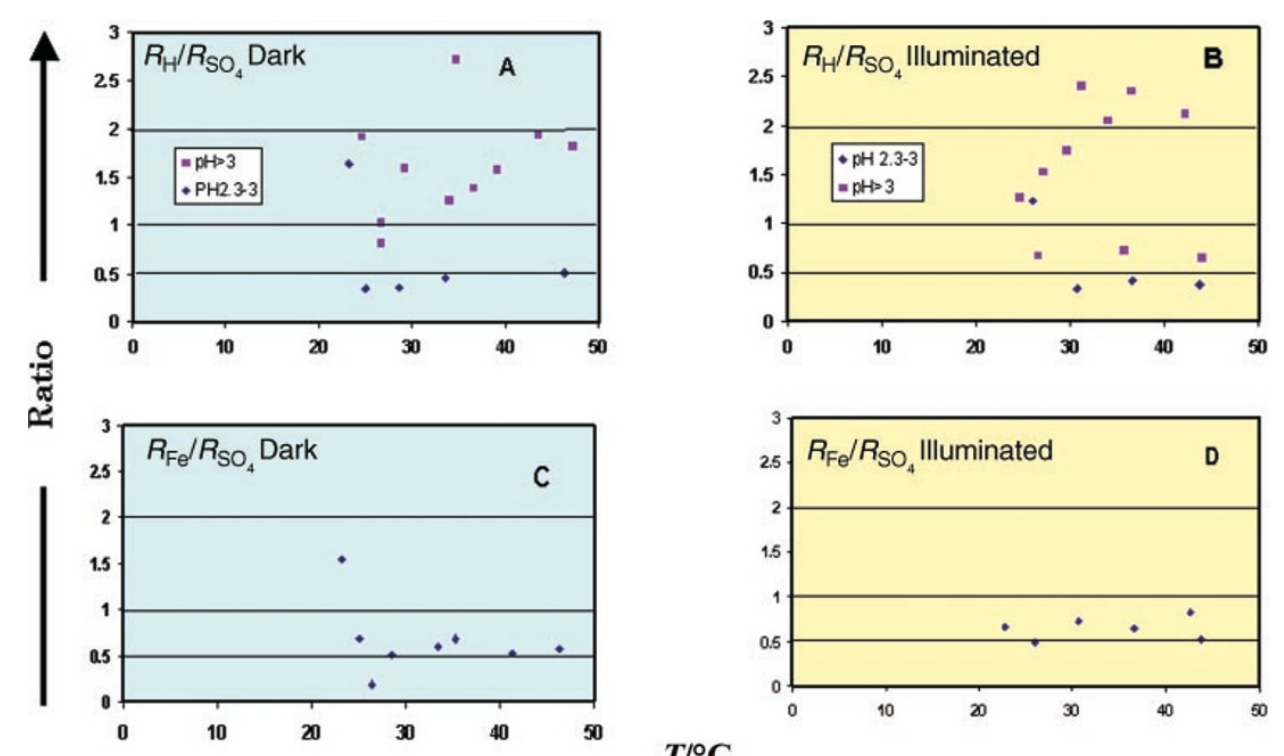

$T /{ }^{\circ} \mathrm{C}$

Fig. 8 Comparison of rates based on $R_{\mathrm{H}}, R_{\mathrm{SO}_{4}}, R_{\mathrm{Fe}}$. See text for details.

the two data points labelled with a question mark were measured when the reaction progress had reached $2.5 \%$.

\section{Stoichiometry of the reaction}

The stoichiometry of the reaction, as defined by the ratios $R_{\mathrm{H}} /$ $R_{\mathrm{SO}_{4}}$ and $R_{\mathrm{Fe}} / R_{\mathrm{SO}_{4}}$, deviates from the ratios expected on the basis of the overall reaction ratios presented above [(1)-(3) and (7)], see Fig. 8. Below pH 3.5, conditions where reaction (1) is expected to represent the overall process, $R_{\mathrm{H}} / R_{\mathrm{SO}_{4}}$ should be close to 1 and $R_{\mathrm{Fe}} / R_{\mathrm{SO}}$ should be close to 0.5 . As illustrated in Fig. 8(a) and 7(b), $R_{\mathrm{H}} / R_{\mathrm{SO}_{4}}$ is for all but one rate measurement at $23{ }^{\circ} \mathrm{C}$ closer to 0.5 than 1.0 . In the experiments above $\mathrm{pH} 3$, $R_{\mathrm{H}} / R_{\mathrm{SO}_{4}}$ values tend to fall between 1 and 2 , but there is considerable scatter in the data. Illumination does not seem to influence the value of $R_{\mathrm{H}} / R_{\mathrm{SO}_{4}}$

While $R_{\mathrm{H}} / R_{\mathrm{SO}_{4}}$ values seem to be independent of illumination, $R_{\mathrm{Fe}} / R_{\mathrm{SO}_{4}}$ are slightly higher in experiments where the slurries were illuminated than in experiments where the slurries were kept in the dark [Fig. 8(c),(d)]. However, the number of data points is so limited that it may have no physical meaning. Irrespective of whether the slurries were illuminated or not, the $R_{\mathrm{Fe}} / R_{\mathrm{SO}_{4}}$ are higher than the expected value of 0.5 , except for a few experiments near $20^{\circ} \mathrm{C}$.

\section{pH dependence of reaction rate}

Given the questionable accuracy of the BET measurements on the starting materials, combined with the fact that four different batches of starting materials were used, there is very little data that can be used to evaluate the $\mathrm{pH}$ dependence. Fig. 9 shows $R_{\mathrm{SO}_{4}}$ measurements made at temperatures between 40 and $46^{\circ} \mathrm{C}$ on the same starting material at $\mathrm{pH} 2.3,3$, and 5. This set of data was chosen because it spans the largest $\mathrm{pH}$ range. Only data above $40^{\circ} \mathrm{C}$ are shown because at these temperatures the reaction is fast and rates can be more accurately measured. Although based on a limited set of rate data, it appears that the rate of oxidation is strongly dependent on $\mathrm{pH}$. The reaction rate appears to be rising faster with $\mathrm{pH}$ in experiments where the slurry was illuminated.

\section{Temperature dependence}

The rate of pyrite oxidation increases with temperature, but the temperature dependence calculated on the basis of different progress variables does not always agree (Table 2). The Arrhenius plots for each of the three variables determined in

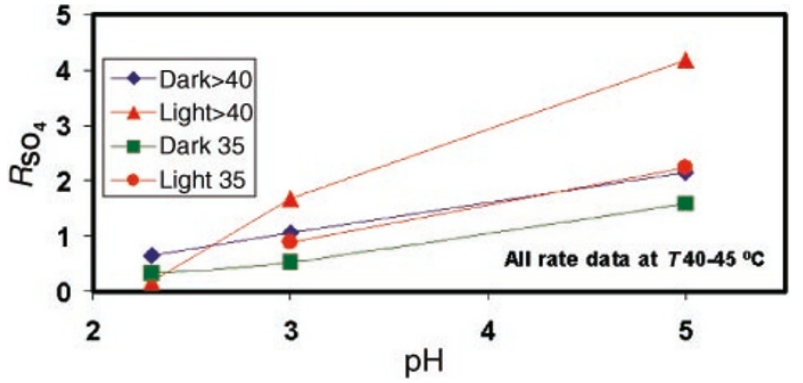

Fig. 9 Comparison of rate data measured at temperatures in excess of $35^{\circ} \mathrm{C}$ on the same starting material. Pyrite oxidation rates increase with $\mathrm{pH}$, but the increases are somewhat sharper when the material is illuminated.

the experiment at $\mathrm{pH} 3$ (Fig. 4) give reasonably consistent activation energies for rate measurements in the dark (48 to $56 \mathrm{kcal} \mathrm{mol}^{-1}$ ) [Fig. 10(a)], but those calculated on the basis of measurements in the light vary considerably $\left(55-86 \mathrm{~kJ} \mathrm{~mol}^{-1}\right)$ [Table 2, Fig. 10(b)]

\section{Discussion}

The rate of pyrite oxidation is strongly temperature dependent, but it is difficult to cast the dependence into a simple Arrhenius equation because the value of the activation energy cannot be uniquely defined. For many experiments we found that the value of the activation energy depends on the choice of progress variable (Table 2). Perhaps it is not surprising though that in a process with many sequential steps the calculated activation energy differs depending on the choice of progress variable. Unless all species used as progress variables undergo identical elementary steps, the activation energy calculated based on different progress variables may be different. This notion is illustrated in Fig. 11. Fig. 11(a) shows the classical reaction coordinate picture with reactants undergoing a multi-step reaction. ${ }^{57}$ An activation energy is associated with each of these steps. The step with the highest activation energy relative to the preceeding intermediate or reactant is the rate-limiting step. ${ }^{58}$ If all three species undergo exactly the same sequence of steps, then no matter which of these species is chosen as a reaction progress variable the calculated activation energy should be the same. The result is different if the species used as reactions progress variables are released to solution at different steps in the reaction sequence. A hypothetical scenario is shown in 
Table 2 Reported and calculated activation energies

\begin{tabular}{|c|c|c|c|c|c|}
\hline $\mathrm{pH}$ range & $T$-range $/{ }^{\circ} \mathrm{C}$ & Progress variable & Dark/light & $E_{\mathrm{a}} / \mathrm{kJ} \mathrm{mol}^{-1}$ & Reference $^{a}$ \\
\hline $2-4$ & $20-40$ & $R_{\mathrm{Fe}}$ & Dark & $56.9+/-7.5$ & $\mathrm{MB}^{b}$ \\
\hline $6.7 \mathrm{~h} ; 8.5$ & $3-25$ & $R_{\mathrm{SO}_{4}}$ & Dark & 88 & $\mathrm{~N}$ \\
\hline 11.4 & $50-80$ & Py loss & Dark & 55.6 & CO-A1 \\
\hline $10-12.5$ & $50-84$ & Py loss & Dark & 60.9 & CO-A2 \\
\hline $5.4-6.4$ & $25-37$ & $R_{\mathrm{O}_{2}}$ & Dark & $62.7+/-12.2$ & $\mathrm{KO}^{b c}$ \\
\hline $5.4-6.4$ & $25-37$ & $R_{\mathrm{O}_{2}}^{2}$ & Dark & $66.1+/-5.9$ & $\mathrm{KO}^{b d}$ \\
\hline 3 & $20-47$ & $R_{\mathrm{H}}^{2}$ & Dark & 54.4 & This study \\
\hline 4 & $20-47$ & $R_{\mathrm{H}}$ & Dark & 100.3 & This study \\
\hline 5 & $20-47$ & $R_{\mathrm{H}}$ & Dark & 64.6 & This study \\
\hline 6 & $20-47$ & $R_{\mathrm{H}}$ & Dark & 72.0 & This study \\
\hline 3 & $20-47$ & $R_{\mathrm{H}}$ & Light & 85.3 & This study \\
\hline 4 & $20-47$ & $R_{\mathrm{H}}$ & Light & 121.1 & This study \\
\hline 5 & $20-47$ & $R_{\mathrm{H}}$ & Light & 48.9 & This study \\
\hline 6 & $20-47$ & $R_{\mathrm{H}}$ & Light & 55.2 & This study \\
\hline 2.3 & $20-47$ & $R_{\mathrm{SO}_{4}}$ & Dark & 50.7 & This study \\
\hline 3 & $20-47$ & $R_{\mathrm{SO}_{4}}$ & Dark & 48.3 & This study \\
\hline 4 & $20-47$ & $R_{\mathrm{SO}_{4}}$ & Dark & 70.8 & This study \\
\hline 5 & $20-47$ & $R_{\mathrm{SO}_{4}}$ & Dark & 34 & This study \\
\hline 6 & $20-47$ & $R_{\mathrm{SO}_{4}}$ & Dark & 45 & This study \\
\hline 3 & $20-47$ & $R_{\mathrm{SO}_{4}}$ & Light & 64.2 & This study \\
\hline 4 & $20-47$ & $R_{\mathrm{SO}_{4}}$ & Light & 74.5 & This study \\
\hline 5 & $20-47$ & $R_{\mathrm{SO}_{4}}$ & Light & 89 & This study \\
\hline 6 & $20-47$ & $R_{\mathrm{SO}_{4}}$ & Light & 64 & This study \\
\hline 2.3 & $20-47$ & $R_{\mathrm{Fe}}{ }^{4}$ & Dark & 46.2 & This study \\
\hline 3 & $20-47$ & $R_{\mathrm{Fe}}$ & Dark & 56.3 & This study \\
\hline 3 & $20-47$ & $R_{\mathrm{Fe}}$ & Light & 55.8 & This study \\
\hline
\end{tabular}

Fig. 11(b). Here $\mathrm{C}$ is released to solution before $\mathrm{A}$ and $\mathrm{B}$. In this scenario the rate-limiting step for the release of $\mathrm{C}$ is step 1 with $E_{\mathrm{a}, 1}$, but for the release of $\mathrm{A}$ and $\mathrm{B}$ the rate limiting step is step 2 with $E_{\mathrm{a}, 2}$. In essence, the $E_{\mathrm{a}}$ calculated on the basis of a progress variable $i$ is the $E_{\text {a }}$ associated with the rate-limiting step for the formation of species $i$. The fact that the ratios of the rates of sulfate release, proton release and iron release vary with temperature and possibly with $\mathrm{pH}$ indicates that these three species are not released at the same rate. Furthermore,

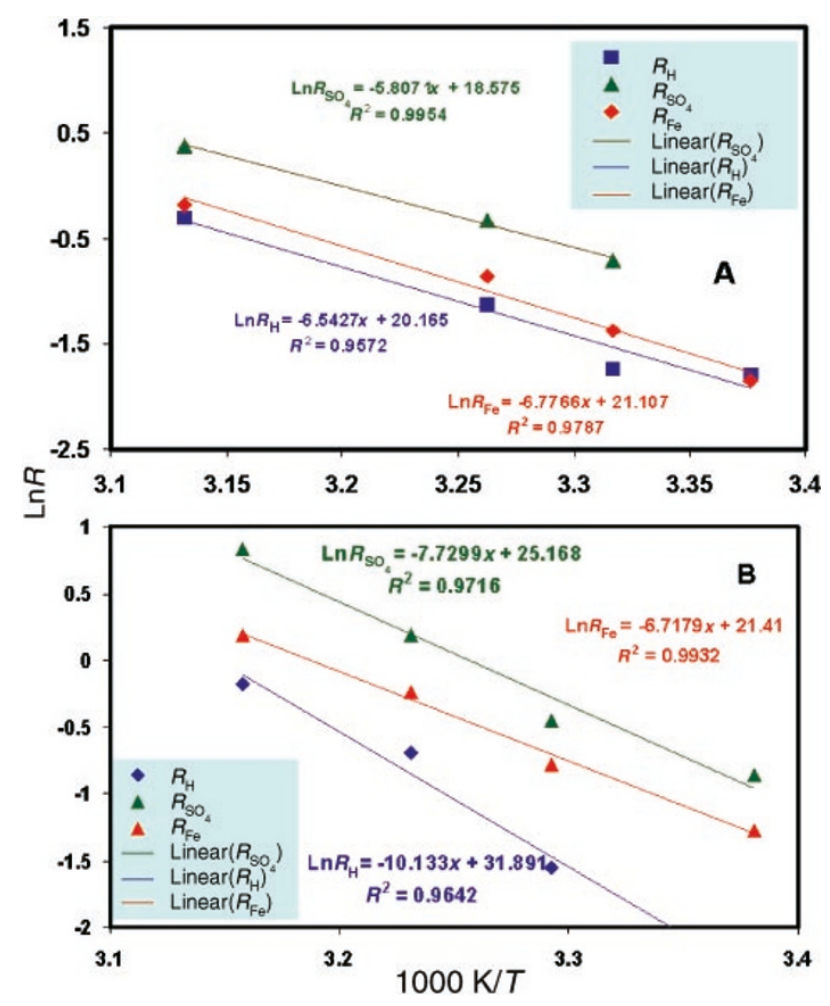

Fig. 10 Arrhenius plots for each of the three progress variables determined in experiment P21 in the dark (A) and light (B).
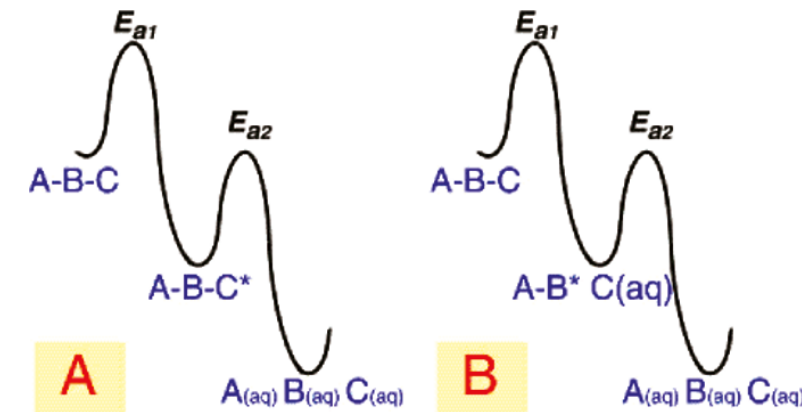

Fig. 11 Schematic diagram of reaction coordinate of hypothetical twostep reaction. Note that in panel A the activation energy on the basis of any of the three aqueous species should be the same. However, in B, the activation energy based on the formation of $\mathrm{C}(\mathrm{aq})$ will be different from the activation energy calculated on the basis of $\mathrm{A}(\mathrm{aq})$ and $\mathrm{B}(\mathrm{aq})$.

because these three species are likely to undergo a different set of elementary step before they are released to solution, $R_{\mathrm{H}}$, $R_{\mathrm{SO}_{4}}$, and $R_{\mathrm{Fe}}$ may have very different temperature dependences and the reaction mechanisms may show a different dependence on $\mathrm{pH}$ and illumination. We believe that differences in elementary steps leading to the release of iron and sulfate cause the discrepancy in reported activation energy for pyrite oxidation (see Table 2). This notion of a bifurcation in the reaction pathway is consistent with surface science studies. ${ }^{59}$ This problem has not been recognized before, because in all other studies the activation energies for pyrite oxidation have been calculated on the basis of a single progress variable.

On the basis of the earlier spectroscopic surface studies, as well as the $R_{\mathrm{Fe}} / R_{\mathrm{SO}_{4}}$ ratios determined in this study, we postulate that in solutions with $\mathrm{pH}<3.0$ iron is released faster to solution than sulfate. Sulfate is formed via a series of surface reactions in which surface-bound disulfide is stepwise oxidized to sulfate. The oxidation of disulfide to sulfate must involve several elementary steps because in an elementary electrontransfer step a maximum of two electrons can be transferred. Hence, the formation of sulfate involves several steps in which iron may not be involved [cf. Fig. 10(b)]. While in the dark at 
$\mathrm{pH} 3$, the activation energies on the basis of $R_{\mathrm{H}}, R_{\mathrm{SO}_{4}}$, and $R_{\mathrm{Fe}}$ are all around 50 to $55 \mathrm{~kJ} \mathrm{~mol}^{-1}$, this changes under illumination. Under illumination, $E_{\mathrm{a}}$ values on the basis of $R_{\mathrm{H}}$ and $R_{\mathrm{SO}_{4}}$ increase to 85 and $64.2 \mathrm{kcal} \mathrm{mol}^{-1}$, respectively. By contrast, $E_{\mathrm{a}}$ on the basis of $R_{\mathrm{Fe}}$ remains the same. The difference in response to illumination suggests that exposure of pyrite to visible light changes the reaction mechanism for the formation of sulfate and protons, but not for the formation of iron.

The effect of light on the rate of pyrite oxidation is relatively subtle. The overall effect on the rate of pyrite oxidation is typically less than a doubling in rate, and in some experiments not more than a 20 to $30 \%$ increase in rate is seen. Given that the experiments conducted in this study were carried out at a light intensity approximately ten times the normal solar intensity on Earth, it is doubtful that the effect of light has significant consequences on the rate of pyrite oxidation in the environment.

Two effects may contribute to the increase in reaction rate under illumination in this study. These effects are a change in reaction mechanism triggered by a photochemical reaction or a light-induced heating of the pyrite surface. Differences in $E_{\text {a }}$ between $R_{\mathrm{H}}$ and $R_{\mathrm{SO}_{4}}$ measured in the dark and under illumination, as well as changes in $R_{\mathrm{H}} / R_{\mathrm{SO}_{4}}$ and $R_{\mathrm{Fe}} / R_{\mathrm{SO}_{4}}$ ratios suggest that exposure to visible light brings about changes in reaction mechanism. As pointed out above, illumination may change the composition of the surface (4) and it may also produce radicals [reactions (5), (6)]. The UHV experiment, however, shows no clear evidence for a change in surface composition so reaction (4) may play a limited role at best. Nevertheless, reactions (5) and (6) may promote the reaction and change the stoichiometry. Furthermore, it is possible that transformation of some dissolved molecular oxygen to more reactive forms (e.g., singlet $\mathrm{O}_{2}$, superoxide, or peroxide $\left.{ }^{60}\right)$ accelerates the stepwise oxidation of surface-bound disulfide to sulfate. The activation energy calculated on the basis of $R_{\mathrm{Fe}}$ does not change very much and this may indicate that the illumination affects reactions that liberate sulfate and protons, but not iron. We are currently studying the photochemistry of this system in more detail to resolve which reactions may take place.

Light-induced heating of the slurry, as demonstrated in the control experiments, accounts for some of the increase in reaction rate experimentally observed under illumination. Exposure of pyrite to photons with an energy equal or larger than the band gap energy heats the material, as most of the photoelectron-hole pairs created by the interaction between photons and pyrite recombine. The control experiments showed that the temperature of the slurry increased almost immediately by $1.5^{\circ} \mathrm{C}$. This increase in observed temperature is caused by a heating of the pyrite particles, and it is presumed that the temperature of the pyrite surface, where the oxidation reaction takes place, is somewhat higher. Evaluating the temperature at the pyrite surface is difficult, because it depends on the photon flux as well as the efficacy of the dissipation of the heat from the particles to the solution. We suspect, however, that the difference between the surface temperature and experimentally observed temperature is approximately constant over the relatively small temperature range used in this study. Within experimental error, the activation energies quoted in this study in the illuminated experiments would not be expected to be significantly affected by a small error in the absolute temperature (see Fig. 12). Hence, we argue that the pyrite exposed to light exhibits a different activation energy for its oxidation (using $\mathrm{H}^{+}$or $\mathrm{SO}_{4}$ as the progress variable) than pyrite in the dark.

In addition to the differences in activation energy for the oxidation of pyrite with and without photons, the data also suggest that there is a change in oxidation mechanism as a function of $\mathrm{pH}$. As shown in Fig. 13, at $\mathrm{pH} 5$ and 6 the activation energy on the basis of $R_{\mathrm{H}}$ shows a lower activation

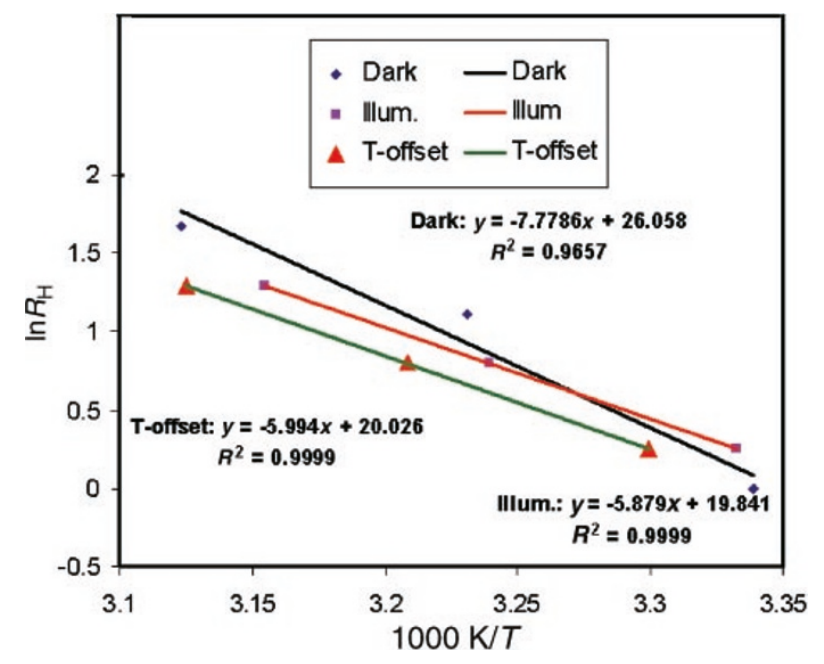

Fig. 12 Arrhenius plot for the rate of oxidation of pyrite determined in the dark and under illumination. Because the surface temperature of the pyrite particles under illumination is higher than the measured temperature in the slurry, the activation energy should be higher than the value derived from the slope of the Arrhenius plot. However, even if the temperatures are increased by $3{ }^{\circ} \mathrm{C}$ at each of the reported temperatures to take into account the effect of light-induced heating of the surface (see text), the activation energy from the temperatureadjusted plot is essentially the same as the activation energy based on the recorded temperatures in the experiment under illumination. This suggests that illumination induces a change in reaction mechanism; the difference in activation energy cannot be accounted for by a simple temperature correction.

energy under illumination than in the absence of light. In experiments below $\mathrm{pH}$, however, $E_{\mathrm{a}}$ on the basis of $R_{\mathrm{H}}$ is higher under illumination than in the dark. Hence, the $\mathrm{pH}$ dependences of the activation energies for pyrite oxidation in the light and dark are different. Furthermore, inspection of the activation energy data for sulfate production (bottom portion of Fig. 13) shows that this parameter for the illuminated pyrite remains greater than the dark case throughout the $\mathrm{pH}$ range

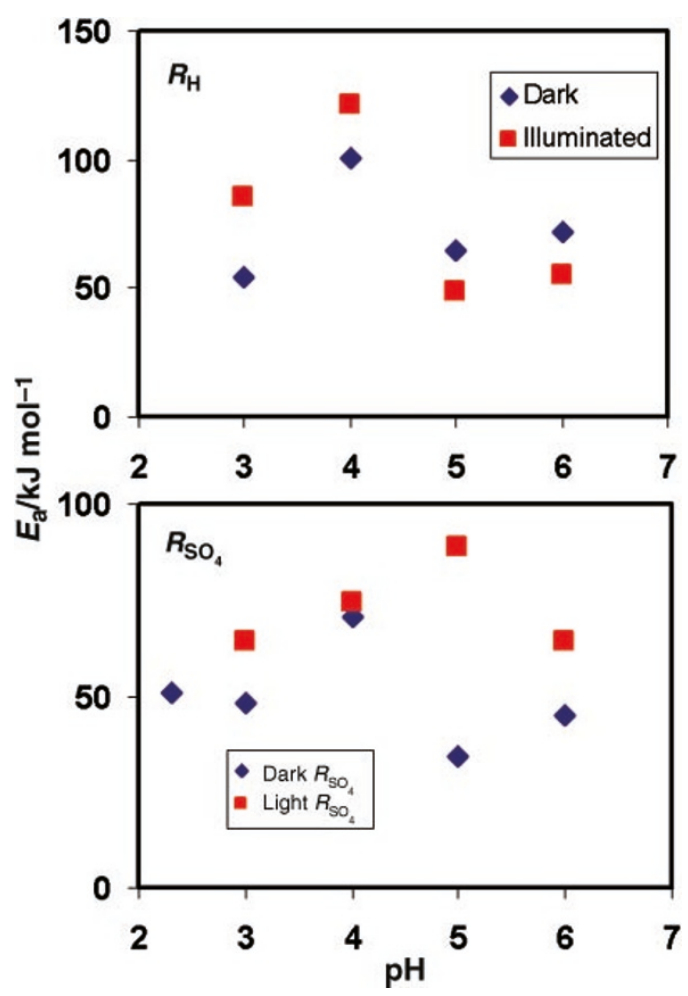

Fig. 13 Activation energies on the basis of $R_{\mathrm{H}}$ (top panel) and $R_{\mathrm{SO}_{4}}$ (bottom panel) as a function of $\mathrm{pH}$. 
used in this study. This result suggests that illumination of the pyrite affects the activation energy for $\mathrm{H}^{+}$production differently to $\mathrm{SO}_{4}$ production. More generally, this result further emphasizes that irradiation of pyrite with visible light affects its fundamental surface oxidation reactivity. Unfortunately, there is too little data on the rate of iron release to evaluate if illumination changes the mechanism by which iron is released. At pH 3, $E_{\mathrm{a}}$ on the basis of $R_{\mathrm{Fe}}$ is the same for measurements under illumination and in the dark, but more experiments would be needed to verify this possibility.

\section{Conclusions}

The data presented in this manuscript support the following conclusions:

(i) The oxidation rate of pyrite is strongly temperature dependent, but it is not straightforward to describe the temperature dependence in the form of an Arrhenius equation. It appears that there is no unique activation energy for the process as $E_{\mathrm{a}}$ values differ as a result of the choice of progress variable.

(ii) Results suggest that the oxidations of the sulfur and iron component of pyrite proceed relatively independently of each other.

(iii) The effect of illumination with visible light is subtle. There is a change in reaction mechanism below $\mathrm{pH} 5$, as indicated by changes in $R_{\mathrm{H}} / R_{\mathrm{SO}}$ ratio. Some of the enhanced reaction rate under illumination may simply be the result of a light-induced thermal effect.

(iv) The rate of pyrite oxidation increases with $\mathrm{pH}$ between pH 2.3 and 6.0.

(v) $R_{\mathrm{H}}$ is a useful reaction progress variable above $\mathrm{pH} 2.3$.

\section{Acknowledgements}

This study has been made possible by grants from DOE-BES (DEFG0296ER14644, DEFG0296ER14633 to DS and MS, respectively). We thank Dr Hiroshi Ohmoto, Penn State University, for making his recent work with Dr Kamei available to us before publication. We thank two anonymous reviewers for prompt and thorough reviews. The senior author is most grateful for the guidance and support Dr H. L. Barnes has provided over the years.

\section{References}

1 P. Brimblecombe, Human influence on the sulfur cycle, in Evolution of the biogeochemical sulfur cycle, ed. P. Brimblecombe and A. L. Lein, NY, 1989, p. 77.

2 M. A. A. Schoonen, Sulfur cycle, in Encyclopedia of Geochemistry, ed. C. P. Marshall and R. W. Fairbridge, Kluwer, Dordrecht, 1999, p. 608.

3 P. C. Singer and W. Stumm, Acidic mine drainage: The ratedetermining step, Science, 1970, 167, 1121.

4 K. J. Edwards, T. M. Gihring and J. F. Banfield, Seasonal variations in microbial populations and environmental conditions in an extreme acid mine drainage environment, Appl. Environ. Microbiol., 1999, 65, 3627.

5 K. J. Edwards, B. M. Goebel, T. M. Rodgers, M. O. Schrenk, T. M. Gihring, M. Cardona, B. Hu, M. M. McGuire, R. J. Hamers and N. R. Pace, Geomicrobiology of pyrite $\left(\mathrm{FeS}_{2}\right)$ dissolution: Case Study at Iron Mountain, California, Geomicrobiol. J., 1999, 16, 155.

6 M. O. Schrenk, K. J. Edwards, R. M. Goodman, R. J. Hamers and J. F. Banfield, Distribution of Thiobacillus ferrooxidans and Leptospirillum ferrooxidans: Implications for generation of acid mine drainage, Science, 1998, 279, 1519.

7 G. Meyer, C. Waschkies and R. F. Huttl, Investigations on pyrite oxidation in mine spoils of the Lusatian mining district, Plant Soil, 1999, 213, 137.

8 D. K. Nordstrom and G. Southam, Geomicrobiology of sulfide mineral oxidation, in Geomicrobiology: Interactions between
Microbes and Minerals, ed. J. F. Banfield and K. H. Nealson, 1997, p. 361.

9 K. J. Edwards, P. L. Bond, T. M. Gihring and J. F. Banfield, An Archaeal iron-oxidizing extreme acidophile important in acid mine drainage, Science, 2000, 287, 1796.

10 R. V. Nicholson, R. W. Gillham and E. J. Reardon, Pyrite oxidation in carbonate-buffered solution: 1. Experimental kinetics, Geochim. Cosmochim. Acta, 1988, 52, 1077.

11 C. O. Moses, D. K. Nordstrom, J. S. Herman and A. L. Mills, Aqueous pyrite oxidation by dissolved oxygen and by ferric iron, Geochim. Cosmochim. Acta, 1987, 51, 161.

12 H. F. Steger and D. L. E., Oxidation of sulfide minerals. 4 Pyrite, chalcopyrite and pyrrhotite, Chem. Geol., 1978, 23, 225.

13 C. O. Moses and J. S. Herman, Pyrite oxidation at circumneutral pH, Geochim. Cosmochim. Acta, 1991, 55, 471.

14 R. V. Nicholson, R. W. Gillham and E. J. Reardon, Pyrite oxidation in carbonate-buffered solution: 2 . Rate control by oxide coatings, Geochim. Cosmochim. Acta, 1989, 54, 395.

15 V. P. Evangelou, Pyrite oxidation and its control, CRC Press, Boca Raton, FL, 1995

16 M. McKibben and H. Barnes, Oxidation of pyrite in low temperature acidic solutions: Rate laws and surface textures, Geochim. Cosmochim. Acta, 1986, 50, 1509.

17 M. A. Williamson and J. D. Rimstidt, The kinetics and electrochemical rate-determining step of aqueous pyrite oxidation, Geochim. Cosmochim. Acta, 1994, 58, 5443.

$18 \mathrm{~K}$. Buker and H. Tributsch, Photoelectrochemistry of highly Zndoped pyrite as compared with isostructural $\mathrm{FeS}_{2}, J$. Electrochem. Soc., 1999, 146, 261.

19 D. Wei and K. Osseo-Asare, Semiconductor electrochemistry of particulate pyrite: dissolution via hole and electron pathways, J. Electrochem. Soc., 1996, 143, 3192.

20 S. Lalvani and M. Shami, Electrochemical oxidation of pyrite slurries, J. Electrochem. Soc., 1986, 133, 1364.

21 E. Ahlberg and A. E. Broo, Electrochemical reaction mechanisms at pyrite in acidic perchlorate solutions, J. Electrochem. Soc., 1997, 144, 1281 .

22 K. K. Mishra and K. Osseo-Asare, Aspects of the interfacial electrochemistry of semiconductor Pyrite $\left(\mathrm{FeS}_{2}\right)$, J. Electrochem. Soc., 1988, 135, 2502.

23 D. Wei and K. Osseo-Asare, Semiconductor electrochemistry of particulate pyrite, J. Electrochem. Soc., 1997, 144, 546.

24 H. W. Nesbitt and I. J. Muir, X-ray photoelectron spectroscopic study of a pristine pyrite surface reacted with water vapour and air, Geochim. Cosmochim. Acta, 1994, 58, 4667.

25 J. R. Mycroft, G. M. Bancroft, N. S. McIntyre, J. W. Lorimer and I. R. Hill, Detection of sulfur and polysulfides on electrochemically oxidized pyrite surfaces by X-ray photoelectron spectroscopy and Raman spectroscopy, J. Electroanal. Chem., 1990, 292, 139.

26 J. Guevremont, D. R. Strongin and M. A. A. Schoonen, Effects of surface imperfections on the binding of $\mathrm{CH}_{3} \mathrm{OH}$ and $\mathrm{H}_{2} \mathrm{O}$ on $\mathrm{FeS}_{2}(100)$ : using adsorbed $\mathrm{Xe}$ as a probe of mineral structure, Surf. Sci., 1997, 391, 109.

27 J. M. Guevremont, D. R. Strongin and M. A. A. Schoonen, Photoemission of adsorbed xenon, X-ray Photoelectron spectroscopy, and Temperature-Programmed Desorption studies of $\mathrm{H}_{2} \mathrm{O}$ on $\mathrm{FeS}_{2}(100)$, Langmuir, 1998, 14, 1361.

28 J. M. Guevremont, D. R. Strongin and M. A. A. Schoonen, Thermal chemistry of $\mathrm{H}_{2} \mathrm{~S}$ and $\mathrm{H}_{2} \mathrm{O}$ on the striated (100) plane of pyrite: Unique reactivity of defect sites, Am. Mineral., 1998, 83, 1246.

29 J. Guevremont, J. Bebié, D. R. Strongin and M. A. A. Schoonen, Reactivity of the (100) plane of pyrite in oxidizing gaseous and aqueous environments: effects of surface imperfections, Environ. Sci. Technol., 1998, 32, 3743.

30 J. M. Guevremont, A. R. Elsetinow, D. R. Strongin, J. Bebié and M. A. A. Schoonen, Structure sensitivity of pyrite oxidation: Comparison of the (100) and (111) planes, Am. Mineral., 1998, 83, 1353.

31 C. M. Eggleston and M. F. Hochella, Scanning tunneling microscopy of pyrite $\{100\}$ : Surface structure and step reconstruction, Am. Mineral., $1992,77,221$.

32 A. R. Elsetinow, J. M. Guevremont, D. R. Strongin and M. A. A. Schoonen, Oxidation of $\{111\}$ and $\{100\}$ planes of pyrite: effects of surface atomic structure and preparation method, Am. Mineral., 2000, 85, 623.

33 W. X. Guo, R. R. Parizek and A. W. Rose, The role of thermalconvection in resupplying $\mathrm{O}_{2}$ to strip coal-mine spoil, Soil Sci., 1994, 158, 47.

34 W. X. Guo and R. R. Parizek, Field-research on thermal anomalies indicating sulfide-oxidation reactions in mine spoil, in 
Environmental geochemistry of sulfide oxidation, ed. D. Blowes and C. Alpers, Washington DC, 1994, p. 645.

35 G. Chen, Z. J. F. Fan and A. J. Bard, Electrochemical investigation of the energetics of irradiated $\mathrm{FeS}_{2}$ (pyrite) particles, J. Phys. Chem., 1991, 95, 3682.

36 V. Balzani and F. Scandola, Interaction between light and matter, in Photocatalysis: Fundamentals and Applications, ed. N. Serpone and E. Pelizetti, New York, 1989, p. 9.

37 R. J. Borg and G. J. Dienes, The physical chemistry of solids, Academic Press, New York, 1992.

38 S. R. Morrison, The chemical physics of surfaces, Plenum, New York, 1990.

39 M. Gratzel, Heterogeneous photochemical electron transfer, CRC Press, Boca Raton, FL, 1989.

40 M. Gratzel, Photocatalysis with colloidal semiconductors and polycrystalline films, in Photocatalysis and Environment, ed. M. Schiavello, Kluwer, Dordrecht, 1988, p. 367.

41 M. Gratzel, Colloidal semiconductors, in Photocatalysis: Fundamentals and Applications, ed. N. Serpone and E. Pelizetti, New York, 1989, p. 123.

42 M. A. A. Schoonen, Y. Xu and D. R. Strongin, An introduction to geocatalysis, J. Geochem. Explor., 1998, 62, 201.

43 T. Waite, Photo-redox complexes at the mineral-water interface, in Mineral-water interface geochemistry, ed. M. F. Hochella and A. F. White, Washington, DC, 1990, p. 559

$44 \mathrm{Y}$. Xu and M. A. A. Schoonen, The absolute energy position of conduction and valence bands of selected semiconducting minerals, Am. Mineral., 2000, 85, 543.

45 A. J. Bard, R. Parsons and J. Jordan, Standard potentials in aqueous solution, Marcel Dekker, New York, 1985.

46 R. G. Pearson, Symmetry rules for chemical reactions, John Wiley \& Sons, New York, 1976

47 G. W. Luther, The frontier-molecular-orbital theory approach in geochemical processes, in Aquatic Chemical Kinetics, ed. W. Stumm, New York, 1990, p. 173.

48 K. M. Rosso, U. Becker and M. F. J. Hochella, The interaction of pyrite $\{100\}$ surfaces with $\mathrm{O}_{2}$ and $\mathrm{H}_{2} \mathrm{O}$ : Fundamental oxidation mechanisms, Am. Mineral., 1999, 84, 1549.
49 K. M. Rosso, U. Becker and M. F. Hochella, Atomically resolved electronic structure of pyrite $\{100\}$ surfaces: An experimental and theoretical investigation with implications for reactivity, $\mathrm{Am}$. Mineral., 1999, 84, 1535.

50 A. J. Bard and M. S. Wrighton, Thermodynamic potential for the anodic dissolution of n-type semiconductors, J. Electrochem. Soc., 1977, 124, 1706

51 C. M. Eggleston, J. Ehrhardt and W. A. M. Stumm, Surface structural controls on pyrite oxidation kinetics: an XPS-UPS, STM and modeling study, Am. Mineral., 1996, 81, 1036.

52 V. Ciminelli and K. Osseo-Asare, Kinetics of pyrite oxidation in sodium carbonate solutions, Metall. Mater. Trans. B, 1995, 26B, 209.

53 V.S. T. Ciminelli and K. Osseo-Asare, Kinetics of pyrite oxidation in sodium hydroxide solutions, Metall. Mater. Trans. B, 1995 , 26B, 677.

54 G. Kamei and H. Ohmoto, The kinetics of reactions between pyrite and $\mathrm{O}_{2}$-bearing water revealed in in-situ monitoring of $\mathrm{DO}$ EH, and $\mathrm{pH}$ in a closed system, Geochim. Cosmochim. Acta, 2000, in the press.

55 S. L. Murov, I. Carmichael and G. L. Hug, Handbook of photochemistry, Marcel Dekker, New York, 1993.

56 I. B. Butler, M. A. A. Schoonen and D. T. Rickard, Removal of dissolved oxygen from water: A comparison of four common techniques, Talanta, 1994, 41, 211.

57 K. J. Laidler, Chemical kinetics, Harper and Row, New York, 1987.

58 J. R. Murdoch, What is the rate-limiting step of a multistep reaction?, J. Chem. Ed., 1981, 58, 32.

59 A. G. Schaufuss, H. W. Nesbitt, I. Kartio, I. Kartio, K. Laajalehto, G. M. Bancroft and R. Szargan, Incipient oxidation of fractured pyrite surfaces in air, J. Electron Spectrosc. Relat. Phenom., 1998, 96, 69.

60 W. Stumm and J. J. Morgan, Aquatic chemistry: Chemical equilibria and rates in natural waters, Wiley-Interscience, New York, 1995 